\title{
LEVANTAMENTO, CLASSIFICAÇÃO E CATEGORIZAÇÃO DOS INDICADORES DA ATIVIDADE DE PD\&E
}

\section{Suzana Borschiver}

\section{RESUMO}

As empresas vêm aprimorando seu processo de PD\&E 1 industrial quando já existente e implantando novos, no caso de não existente, conscientes da sua necessidade e importância para o alcance de uma competividade sustentável. Um dos problemas relacionados a essa gestão é a avaliação da eficiência e eficácia do processo de PD\&E e seu acompanhamento, através de indicadores que traduzam não somente a aderência dos projetos à estratégia da empresa como também à administração de portifólio desses projetos e dos resultados obtidos a partir de recursos normalmente escassos. 0 presente artigo tem por objetivo fazer um levantamento, classificação e categorização dos indicadores da atividade de PD\&E industrial relacionados na literatura e utilizados em empresas relacionadas com o setor industrial.

Palavras-Chaves: Indicadores de PDE. Gestão empresarial. Competitividade.

\begin{abstract}
Companies have been improving their existing RD\&E processes or initiating them, in the case of those who had not already done so. In both instances, the impetus is an awareness of the necessity and importance of such policies in attaining sustainable competitiveness. One of the challenges presented by this type of management policy is the evaluation of the efficiency and efficacy of the RD\&E process and its monitoring by means of indicators which reflect not only the adherence of projects to company strategy, but also the administration of the portfolio of these projects and the results obtained on the basis of generally scarce resources. The present article, which is part of a post-doctoral business project completed in 2006, aims to survey, classify and categorize indicators of industrial RD\&E activity covered in the literature and used in companies connected to the industrial sector.
\end{abstract}

Keywords: RD\&E Indicators. Business management. Competitiveness.

1 PD\&E de acordo com definição da ANPEI é pesquisa, desenvolvimento e engenharia não rotineira. 


\section{O USO DE INDICADORES NA GESTÃO ESTRATÉGICA DAS EMPRESAS}

Nas últimas décadas, a importância dada à utilização de indicadores nas definições estratégicas da empresas tem aumentado consideravelmente, fruto dos trabalhos desenvolvidos por vários estudiosos, com o intuito de fornecer às empresas uma forma efetiva de gerenciar o desempenho. Uma das maiores contribuições foi dada por Henry Mintzberg, Bruce Ahlstrand e Joseph Lampel com o livro "Safári de estratégia: um roteiro pela selva do planejamento estratégico". Entretanto havia uma lacuna entre a definição de estratégias e sua execução. Robert Kaplan e David Norton, em suas pesquisas sobre indicadores de desempenho e gestão de custos, que resultaram no livro "A estratégia em ação: Balanced Scorecard", completaram esta lacuna entre formulação de estratégias e suas implantações (Aquino, 2001). Esses autores ressaltam que muitos dos atuais sistemas de medição de desempenho não captam os benefícios futuros das iniciativas de melhoria e desenvolvimento em longo prazo, devido aos seus conceitos de mensuração e acumulação, prejudicando e distorcendo o resultado. Assim, os programas de qualidade, treinamentos e desenvolvimento de competências, sistemas de informação, etc, têm sua aceitação dificultada nas decisões. A questão relevante é como mostrar aos gestores os impactos de suas decisões no futuro da empresa e fazê-los agregar experiências com estes impactos, diminuindo o risco nas próximas decisões, principalmente em nível de estratégia. Daí a justificativa de tratar os sistemas de gestão destas empresas para que as decisões de investimento, produção entre outras, estejam ligadas à geração de lucro (como variação do patrimônio) em longo prazo, o real interesse da empresa.

Segundo Frost (1999), até a década de 90, a maioria das organizações usava, para medir seu desempenho, os resultados financeiros e outros poucos não financeiros. Os gerentes definiam seus objetivos, com base nos orçamentos que dispunham. Uma combinação de vários fatores, como o aumento da demanda no mercado, associado a uma competição mais acirrada fez com que o tempo se tornasse mais curto exigindo que tudo fosse melhor, mais rápido e mais barato. Sob estas pressões, ficou claro que o sistema financeiro ajudava às pessoas a gerenciar os budgets e relatórios de resultados, mas não as atividades do negócio que produziam os resultados.

Nos últimos vinte anos, com a aceleração do processo de globalização e o aumento da competição por mercados, as organizações passaram a necessitar de indicadores que possibilitassem uma visão mais exata de seu desempenho para decidir quais estratégias tomar. Indicadores com os quais as empresas pudessem direcionar suas mudanças, conhecer sua posição competitiva, aprimorar seus processos e melhor prever o futuro. Para implementar iniciativas estratégicas e direcionar as empresas para mudanças rápidas, as organizações líderes começaram sistematicamente a incluir em seus planos estratégicos os indicadores de desempenho. No entanto, Meyer (1994) alerta para o erro de se utilizar uma quantidade excessiva de indicadores, sem que estejam relacionados com a estratégia traçada. Para que as decisões sejam corretas, a alta administração deve dispor de todas as informações relevantes oriundas dos indicadores de desempenho. Entretanto, na maioria das vezes, o planejamento estratégico e a definição dos indicadores de desempenho estão dissociados, pela alta administração não participar destes últimos. Deste modo os indicadores de desempenho definidos podem não ser os mais apropriados para o aprimoramento de determinados processos de acordo com a estratégia que foi traçada. 
Corroborando com essa análise, Mafra (1999), apud Harrington (1995), também ressalta a necessidade de associar estratégia ${ }^{2}$ com os indicadores de desempenho, o que geralmente não ocorre na maioria das grandes organizações, onde a alta administração define a visão e a direção a ser tomada, deixando a implementação das ações e controle para seus gerentes. Segundo Harrington (1995), deve-se ter um sistema de indicadores de desempenho que atue de forma decisiva no monitoramento do aprimoramento de processos. Assim deve ser estudado o processo como um todo para se determinar o que medir, controlar e definir indicadores de desempenho que reflitam a eficiência, eficácia e o grau de flexibilidade do processo. Conforme citado anteriormente, Kaplan e Norton (1997) indicam a necessidade da aferição da eficácia das estratégias implementadas em relação aos objetivos estratégicos, levando à necessidade de controle ou realimentação do sistema. Eles utilizam um Balanced Scorecard para controle dos objetivos e metas traçados através da definição de indicadores de desempenho, que melhor comuniquem o significado da estratégia. Como cada estratégia é única, cada Scorecard deve ser único e conter vários indicadores únicos.

Segundo Sink e Tuttle (1993, p.147), a medição tende a ser encarada e usada de maneira muito limitada na maioria das organizações, quanto ao seu exato papel e suas aplicações, seja referente a finanças, contabilidade, padrões de trabalho ou orçamentos.

Walton (1993, p.85), mesmo concordando com esta colocação, entende que, o fato da medição estar voltada para o controle não implica, necessariamente, em uma conotação negativa, ressaltando a importância do desenvolvimento de novos indicadores de desempenho nas organizações, sendo que o desempenho ou a medida de sucesso do negócio não pode mais ser mensurados pelos padrões tradicionais ou orientados somente por extrapolações de fatos ocorridos no passado.

Paleias (1992, p.114), ressalta a necessidade de um referencial e o estabelecimento de intervalos de tempo para a avaliação. Assim, a avaliação de desempenho pressupõe um referencial ou parâmetro para comparação, contra o qual o desempenho será confrontado este parâmetro poderá ser expresso tanto em termos físicos ou financeiros, ou ambos. Do mesmo modo, é necessário o estabelecimento de um intervalo de tempo para que a avaliação de desempenho possa ser feita - este intervalo permitirá operacionalizar tal avaliação, e não necessariamente significa que as atividades sejam paralisadas para que tal avaliação ocorra.

Outra importante questão na apuração do desempenho refere-se às divergências ou pouca clareza dos objetivos fixados, tais como metas financeiras (fluxo de caixa e lucratividade), em relação às metas estratégicas. Segundo Campbell e Alexander (1997, p.3), embora a maioria das empresas aponte, em seus documentos societários, a declaração do objetivo "prover superior retorno do investimento dos acionistas", o desenvolvimento e a manutenção de genuína vantagem competitiva estariam, em verdade, dependentes de estratégias que objetivassem retornos para os "beneficiários" do empreendimento, tradicionalmente representados pelos clientes, fornecedores, empregados e acionistas ${ }^{3}$.

\footnotetext{
${ }^{2}$ A estratégia primordial da organização é determinar seus objetivos e suas intenções a longo prazo, procurando obter uma antevisão do futuro, considerando todo ambiente em que a organização está imersa. A definição dos grandes objetivos (macroobjetivos ou objetivos-chave) a longo prazo é imprescindível para que a organização cumpra o papel que lhe foi atribuído.(Valeriano,2004)

3 Para Drucker (1999, p.38), "a vida média de uma empresa, como organização de sucesso, nunca ultrapassou 30 anos".
} 
Segundo Rummler e Brache (1994, p.170), faz-se necessário prover medidas sólidas que garantam o monitoramento de um sistema de medição total, e não uma coleção de medidas não relacionadas - e potencialmente contraproducentes e um processo de gerenciamento de desempenho que converta os dados fornecidos pelo sistema de medição em ação inteligente. Porém, ao mesmo tempo, o desempenho terá de ser definido de forma não financeira para que tenha significado para os trabalhadores do conhecimento e para que seja capaz de gerar um "compromisso" por parte deles. Esse é um retorno não financeiro de valor. Assim, a estratégia terá, cada vez mais, de ser baseada em novas definições de desempenho.

\section{INDICADORES DENTRO DO CONTEXTO DA INOVAÇÃO}

O processo de inovação tecnológica é, em si, a mudança do próprio paradigma sociocultural associada a uma transformação do padrão de acumulação capitalista, uma das faces de um fenômeno bem mais amplo e profundo vivido pelas sociedades contemporâneas. (Rocha e Ferreira, 2001). 0 aumento na velocidade das mudanças e a globalização fizeram com que a inovação tecnológica passasse a ser considerada vital para a sobrevivência e o crescimento das empresas. Os riscos inerentes a esta atividade exigem a construção de estratégias tecnológicas que estejam a serviço da estratégia global da companhia (Coutinho, 2004).

A inovação tecnológica deve ser preocupação / responsabilidade de todos os setores da empresa. Neste sentido, a atividade deve congregar elementos de várias funções, incluindo aí o chão de fábrica, os engenheiros de processo e produto, os "cientistas", o "marketing" e muitas vezes o próprio cliente. A inovação industrial, nos seus aspectos tecnológicos, pode ser obtida assim a partir dos resultados deste trabalho interno, através da compra ou licenciamento de tecnologias disponíveis e/ou alguma forma de associação entre empresas (Coutinho et al, 2001).

Segundo o Manual de Frascati (2002) ${ }^{4}$, os indicadores demonstram especificidades de um aspecto complexo e, portanto representam uma grande diversidade de fatores, sendo necessário um modelo de referência que descreva o sistema de inovação em que eles se encontram e suas relações de interdependência. Esse cuidado deve ser tomado para evitar que um indicador isoladamente seja supervalorizado em detrimento do macroambiente mascarando as atividades ao seu redor (Pino et al.). 0 sistema de indicadores escolhidos deve ser claro e de fácil manipulação a todos da empresa. Além disso, não se deve gastar muito tempo na compilação desses dados para que os próprios não se tornem improdutivos.

Os indicadores tradicionais de Inovação proporcionam medidas de resumo das atividades inovadoras de empresas, (Arundel, 1998), podendo-se citar como exemplo: as patentes registradas, as publicações científicas e o número de mão de obra ou funcionários exercendo as funções de cientistas e engenheiros em pesquisas, ou seja, os gastos em P\&D.

0 investimento total das empresas em inovação tecnológica corresponde aos gastos realizados em um conjunto de atividades inovadoras, com o objetivo de aumentar o estoque e

\footnotetext{
${ }^{4}$ O Manual de Frascati faz parte do sistema estatístico dos países-membros da OCDE (Organização para a Cooperação e Desenvolvimento Económico). A 1. a versão oficial deste documento (também designado, Proposed Standard Pratice for Surveys of Research and Development), surge em Junho de 1963, do encontro, em Frascati (Itália), de peritos (nacionais) em estatísticas de I\&D. A importância deste documento prende-se com a necessidade de uniformizar estatísticas e criar indicadores fidedignos e comparáveis nesta área, fornecendo definições e classificações aceites internacionalmente.
} 
a aplicabilidade do conhecimento tecnológico, bem como elevar o nível das competências e habilidades dos recursos produtivos da empresa.

Segundo a ANPEI (1998), além do núcleo central, relacionado à aplicação de recursos financeiros nas atividades de "pesquisa e desenvolvimento"(P\&D), os investimentos em inovação tecnológica das empresas compreendem os dispêndios com "serviços de apoio tecnológico" (capacitação de recursos humanos alocados nas atividades de pesquisa e desenvolvimento, ensaios, testes, análises técnicas e informações tecnológicas), com a "aquisição de tecnologia" (royalties pagos pelo uso de marcas e patentes,aquisição de direitos relacionados com novos produtos ou processos, serviços de assistência técnica, aquisição de programas de computador), os gastos com "engenharia não rotineira"(design, rearranjos de plantas requeridas para implementação de novos produtos e processos),os"investimentos físicos" (compra de máquinas,equipamentos e instalações) e os "investimentos intangíveis" (direitos sobre licenças para exploração de patentes e uso de marcas e contratos de fornecimento de tecnologia industrial).

Na Organização de Cooperação para o Desenvolvimento Econômico (OCDE), a concepção de que o progresso da ciência e a mudança tecnológica, propiciados pela interação entre conhecimento e informação, constitui vetor-chave das transformações ora em curso e tem motivado a elaboração de uma vasta gama de estudos e pesquisas, com o objetivo de aprofundar a compreensão sobre a natureza do processo inovador dos países membros, no contexto da nova "economia baseada no conhecimento" (knowledge-based economy).

Algumas iniciativas, como a implementação do projeto "Blue Sky" e do programa de estudos e pesquisas "Reestructuring and reintegration of S\&T systems in economies in transition" (1998) e o aperfeiçoamento da metodologia contida no Manual de Oslo (versão original de 1992 e primeira revisão de 1996), representam ações concretas dos países desenvolvidos no sentido de ampliar o escopo das "políticas de ciência e tecnologia" e de adequar a configuração dos atuais sistemas de informações em C\&T, ajustando-os aos requerimentos impostos pela sociedade do conhecimento.

O principal avanço nessa metodologia (Manual de Oslo) foi a introdução de questões que dessem conta do fato de que o processo de inovação é interativo, em que se envolvem várias funções e atores (figura 1), dentro e fora da empresa, em oposição a uma compreensão seqüencial ou linear, que vê a P\&D como a etapa que "origina" a inovação (Smith, 2000; Archibugi et al., 1995). Dessa forma, essa metodologia propõe a produção de um leque mais abrangente de indicadores para medir o esforço das várias atividades ou funções da empresa que contribuem com insumos ao processo de inovação: além da P\&D interna e externa, a aquisição de direitos de propriedade de conhecimento codificado,a engenharia de projeto, a produção de ferramental e a produção experimental, o marketing de novos produtos e a aquisição de equipamentos e demais despesas de investimento requeridas na implementação de inovações de produto ou processo (FAPESP, 2005). 
Figura 1: Processo de Inovação Tecnológica (Manual de Oslo)

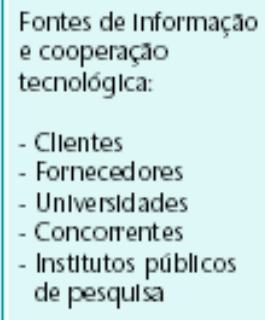

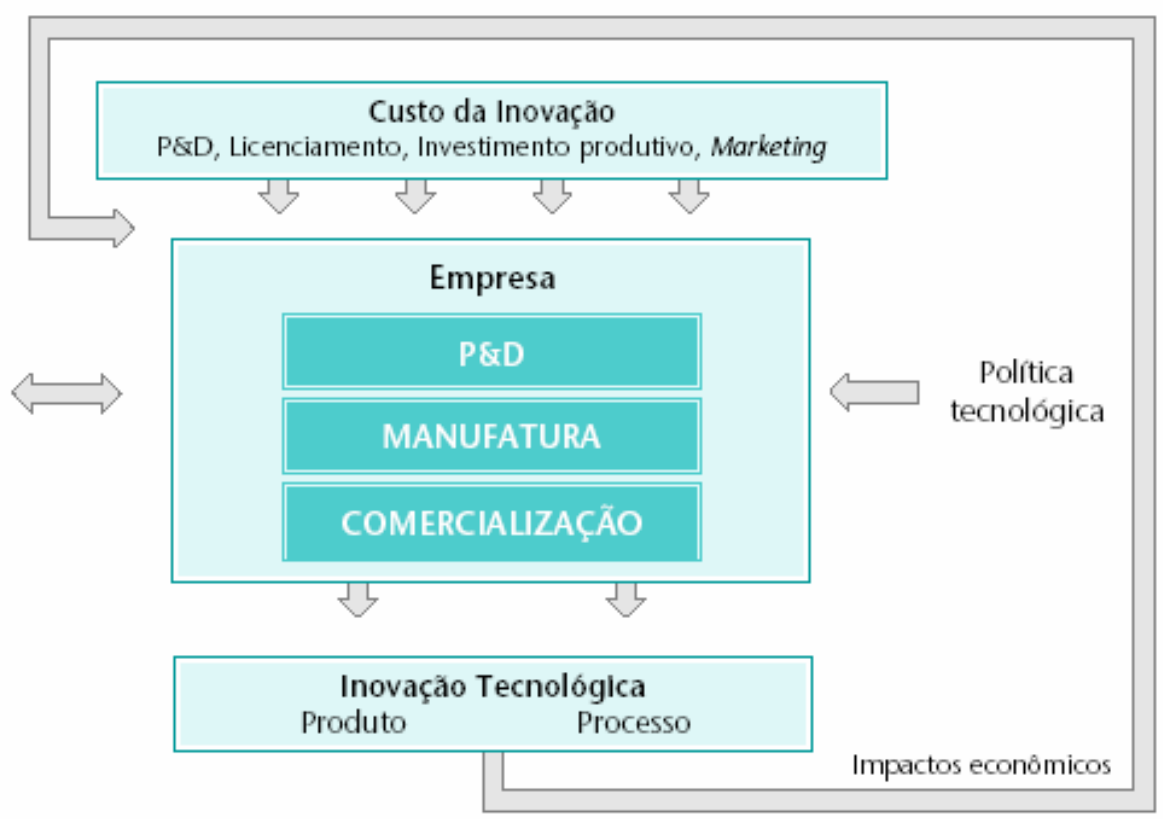

Fonte: OCDE/Eurostat, 1997

0 aspecto sistêmico do processo também foi enfatizado, com a investigação das fontes de informação para a inovação e das formas de cooperação tecnológica que as empresas estabelecem com outras instituições. Além disso, a metodologia propõe a investigação daquilo que parece ser o mais importante do ponto de vista da sociedade: os resultados tecnológicos e impactos econômicos da inovação. A crescente preocupação dos países em compreender a natureza e a complexidade dos processos de inovação tecnológica tem sido acompanhada por uma mudança de foco nas discussões sobre as transformações ocorridas na base tecnoeconômica das sociedades contemporâneas. As abordagens baseadas nas "políticas de ciência e tecnologia" estão sendo gradativamente substituídas pela concepção dos "sistemas nacionais de inovação", tendência que se manifesta, principalmente, a partir dos trabalhos pioneiros de Lundvall (1992) e Nelson (1993) sobre "sistemas nacionais de inovação" (Rocha et al, 2001).

A inovação tecnológica na empresa produtiva é tema com presença crescente no debate público e na elaboração de políticas para o desenvolvimento econômico no Brasil. Em linha com o que tem acontecido nos países mais industrializados, a importância da inovação para a economia do país - num mundo cada vez mais internacionalizado - e a necessidade de incrementar capacidade de inovação das empresas são assuntos por meio dos quais ciência e tecnologia (C\&T) têm deixado de ser de interesse restrito de cientistas e engenheiros para ganhar a atenção do mundo dos negócios. Isso torna crítica a construção de indicadores de inovação que sejam capazes de captar de maneira ampla, mas ao mesmo tempo aguda, os esforços feitos pelas empresas para inovar, como eles se relacionam com suas estratégias e os resultados de seu processo de inovação. A busca de indicadores mais abrangentes e analiticamente mais poderosos tem feito evoluir rapidamente os conceitos e as metodologias para a mensuração da inovação tecnológica.

0 foco restrito nas medidas de pesquisa e desenvolvimento (P\&D),como insumo, e da atividade patentária, como resultado do processo de inovação, tem sido percebido na 
comunidade de pesquisadores e produtores de estatísticas como insuficiente para compreender as diversas facetas importantes desse processo. Isso é ainda mais verdadeiro nos países em desenvolvimento, em que as atividades organizadas de P\&D estão concentradas em um número restrito de empresas, não obstante um conjunto bem maior delas efetivamente se esforce e se engaje em atividades diversas para introduzir inovações tecnológicas em seus produtos e processos com repercussões importantes para sua produtividade competitividade.

No Brasil, o IBGE publicou, em 2001, a primeira experiência de survey de inovação completa, especifica nacional da indústria brasileira nos termos da metodologia proposta pela OCDE/Eurostat, tendo como referência o período 1998-2000, com apoio do Ministério da Ciência e Tecnologia (MCT) e da Financiadora de Estudos e Projetos (FINEP), a PINTEC (Pesquisa Industrial de Inovação Tecnológica) 2001. Recentemente já foi lançada a PINTEC 2005, referente a dados de 2003-2005. Essa pesquisa tem por finalidade a construção de indicadores nacionais e regionais das atividades de inovação tecnológica desenvolvidas nas empresas industriais brasileiras com 10 ou mais pessoas ocupadas. Figuram entre as informações apresentadas nesta publicação aquelas sobre o esforço empreendido para inovar; resultados do processo inovativo; identificação do impacto das inovações no desempenho das empresas; fontes de informação e relações de cooperação estabelecidas com outras organizações; apoio do governo para as atividades inovativas; e identificação dos problemas e obstáculos para a implementação de inovação. A construção de indicadores sobre o processo de inovação tecnológica, alinhados a padrões metodológicos internacionais, contribui para ampliar o entendimento do processo de desenvolvimento industrial e garante sua comparabilidade com dados de outros países (Bastos, 2003).

O conhecimento dos processos de inovação tecnológica, seus determinantes e seus impactos econômicos requerem a construção de indicadores capazes de apontar tendências na população de empresas, indicadores que se refiram à economia como um todo. É isso que torna necessária a abordagem estatística na produção de informações sobre inovação e atividades tecnológicas. Os estudos de caso, embora úteis para o entendimento da natureza da inovação em setores específicos, não dão conta de compreender a criação e a difusão de tecnologias no conjunto dos setores e de sua relação com variáveis críticas para o crescimento, como o investimento e a produtividade (Smith, 2000). Mas estatísticas sobre atividades tecnológicas das empresas constituem terreno relativamente novo e cheio de problemas, em comparação com as demais estatísticas econômicas. Nos países mais industrializados, com boa experiência no assunto, pesquisadores e responsáveis por políticas consideram insatisfatório o desenvolvimento da produção dessas estatísticas. As fontes mais consolidadas e confiáveis - informações sobre atividades de P\&D e patentes - são também as mais criticadas.

Tomando como ponto de partida a visão do processo de inovação como um fenômeno complexo e sistêmico, o Sistema Nacional de Inovação pode ser definido como o conjunto de instituições e organizações responsáveis pela criação e adoção de inovações em um determinado país. (OCDE, Manual de Oslo, 1996, p. 7).

Inovação tecnológica de produto ou processo compreende a introdução de produtos ou processos tecnologicamente novos e melhorias significativas em produtos e processos existentes. Considera-se que uma inovação tecnológica de produto ou processo tenha sido implementada se tiver sido introduzida no mercado (inovação de produto) ou utilizada no processo de produção (inovação de processo). As inovações tecnológicas de produto ou 
processo envolvem uma série de atividades científicas, tecnológicas, organizacionais, financeiras e comerciais. Afirma inovadora é aquela que introduziu produtos ou processos tecnologicamente novos ou significativamente melhorados num período de referência (OCDE, Manual de Oslo, 1996, p.35).

\section{INDICADORES DE PD\&E, PESQUISA, DESENVOLVIMENTO E ENGENHARIA}

Enquanto ciência e tecnologia são conhecimentos classificados em áreas arbitrariamente estabelecidas, a pesquisa, o desenvolvimento e a engenharia são processos que essencialmente visam a obtenção e a utilização desses conhecimentos. Pesquisa é a busca sistematizada de conhecimentos científicos ou tecnológicos, conforme ela se situe na área da ciência ou da tecnologia, sendo chamada de:

- Pesquisa cientifica, pura, básica, ou fundamental quando não é motivada diretamente por qualquer aplicação prática;

- Pesquisa aplicada ou tecnológica, quando visa a resultados objetivos.

Conforme Valeriano (2004), desenvolvimento tecnológico, desenvolvimento experimental ou simplesmente desenvolvimento é o uso sistemático dos conhecimentos, científicos ou tecnológicos, geralmente alcançados por meio de pesquisas, com a finalidade de obter novos produtos ou processos, isto é, bens ou serviços, ou, ainda, para alcançar significativo melhoramento daqueles já existentes. 0 desenvolvimento situa-se entre a pesquisa e a produção, sendo geralmente interposto ainda mais um processo, a engenharia. Neste caso, o desenvolvimento objetiva a viabilização de uma idéia ou concepção e sua materialização por meio de protótipos, modelos de laboratório, instalações-piloto e todos os experimentos que possibilitam passa-se à engenharia.

Engenharia, por sua vez, segundo o mesmo autor, consiste no planejamento, no projeto e na execução do empreendimento que deverá originar um produto ou prestar um serviço, resultados de desenvolvimento. Ela toma designações várias, conforme os setores em que se aplica: engenharia de sistemas, engenharia de produto, engenharia de construção/montagem, engenharia de produção, engenharia de qualidade, engenharia de software, etc.

Conforme foi exposto até aqui, o sistema de indicadores escolhido deve ser claro e de fácil manipulação a todos da empresa. Não se deve gastar muito tempo na compilação desses dados para que os próprios não se tornem improdutivos.

Em relação ao conceito propriamente dito, cabe ressaltar que vários indicadores de pesquisa, desenvolvimento e engenharia são apresentados na literatura para se tentar medir o esforço inovador, apesar de não haver uma consolidação de um modelo único de mensuração da inovação (Pino et al.).

Tomando-se por base os estudos desenvolvidos por Archirbugi (1988), Patel e Pavitt (1995) e Sbragia (1986), os indicadores de inovação/PD\&E mais comumente utilizados em estudos econômicos foram classificados em seis grupos: estatísticas de P\&D, patentes, indicadores macroeconômicos, monitoração direta da inovação, indicadores bibliométricos e técnicas semi-quantitativas. A tabela 1 a seguir comenta um pouco sobre esses grupos, propondo indicadores alocados para os mesmos. 
Tabela 1: Indicadores de Inovação comumente utilizados

\begin{tabular}{|c|c|c|}
\hline Grupo & Comentários & Indicador \\
\hline $\begin{array}{l}\text { Estatisticas de } \\
\text { P\&D }\end{array}$ & $\begin{array}{l}\text { Apresentam com principais vantagens definiçòes } \\
\text { consistentes e dados coletados regularmente. No } \\
\text { entanto, nada garante que os gastos com P\&D } \\
\text { representem, realmente, a introdução ou } \\
\text { aperfeiçoamento de produtos/processos. Além } \\
\text { disso, as estatisticas de } P \& D \text { aplicam-se mellhor } \\
\text { em alguns setores de atividade, como quimico ou } \\
\text { eletro-eletrónico, ao invés de setores tradicionais } \\
\text { ou de informaçầo. }\end{array}$ & $\begin{array}{c}\text { Gastos em } P \& D \text {, mào de obra } \\
\text { alocada em } P \& D \text {, gastos em } P \& D \\
\text { por faturamento bruto da } \\
\text { empresa. }\end{array}$ \\
\hline \multirow[t]{2}{*}{ Patentes } & $\begin{array}{l}\text { As patentes representam o resultado do processo } \\
\text { de inovação, mas devem representar invençóes } \\
\text { significativas o suficiente para arcar com os } \\
\text { custos do patenteamento. Estatisticas } \\
\text { relacionadas com patentes são facilmente } \\
\text { disponiveis e abrangem longos periodos de } \\
\text { tempo No entanto, nem todas as invenções são } \\
\text { patenteadas por representarem segredo industrial }\end{array}$ & $\begin{array}{l}\text { Número de patentes, nimero de } \\
\text { patentes por funcionário de } P \& D \text {. }\end{array}$ \\
\hline & $\begin{array}{l}\text { ou nào serem tecnicamente patenteáveis, como } \\
\text { softwares. O outro problema consiste no fato de } \\
\text { que algumas patentes nunca foram exploradas } \\
\text { por não representarem um sucesso inovador ou } \\
\text { por existirem apenas para não serem } \\
\text { desenvolvidas por terceiros. }\end{array}$ & \\
\hline $\begin{array}{l}\text { Indicadores } \\
\text { macroeconômicos }\end{array}$ & $\begin{array}{l}\text { Os indicadores macroeconômicos possuem a } \\
\text { desvantagem de não considerarem as transaçôes } \\
\text { de transferências entre empresas dentro de um } \\
\text { mesmo pais. Além disso, não possuem dados } \\
\text { consistentes, já que instituições dentro de um } \\
\text { mesmo país costumam a divergirem em relação } \\
\text { aos dados oferecidos. }\end{array}$ & $\begin{array}{c}\text { Balança de pagamentos em } \\
\text { tecnologia, exportação de } \\
\text { produtos de alta e méclia } \\
\text { tecnologia. }\end{array}$ \\
\hline $\begin{array}{c}\text { Monitoração } \\
\text { direta da inovação }\end{array}$ & $\begin{array}{l}\text { Método criado devido às limitações dos outros } \\
\text { grupos. Apresentam como principais limitações } \\
\text { o fato de não ser conseguir mensurar inovações } \\
\text { em processos e não ser consistente quanto a } \\
\text { quantificação. Uma variante dessa técnica é a } \\
\text { classificação das inovações a partir do catálogo } \\
\text { de produtos fomecidos pelas empresas }\end{array}$ & $\begin{array}{l}\text { Contabilizaçào e classificaçào de } \\
\text { aníncios de descobertas de novos } \\
\text { produtos }{ }^{6} \text { publicados na midia } \\
\text { especializada (jomais de negócios } \\
\text { ou de associações de classe, por } \\
\text { exemplo),pesquisa entre } \\
\text { especialistas de P\&D. }\end{array}$ \\
\hline $\begin{array}{c}\text { Indicadores } \\
\text { bibliométricos }\end{array}$ & $\begin{array}{l}\text { A principal limitação do método é estar } \\
\text { direcionado à pesquisa básica. Além disso, o } \\
\text { estudo de Neclenhof (1988) citado em Andreassi } \\
\text { (1999) afinma que esses indicadores são mais } \\
\text { bem utilizados em ciências exatas e biológicas } \\
\text { do que para ciências humanas. }\end{array}$ & $\begin{array}{l}\text { Numero de artigos cientificos ou } \\
\text { de citaçôes em artigos. }\end{array}$ \\
\hline $\begin{array}{l}\text { Técnicas semi- } \\
\text { quantitativas }\end{array}$ & $\begin{array}{l}\text { São indicadores que procuram converter em } \\
\text { unidade métrica as impressóes das pessoas } \\
\text { quanto ao desempenho da atividade de P\&D. }\end{array}$ & $\begin{array}{l}\text { Avaliaçào de desempenho do } \\
\text { departamento de } P \& D \text { segundo } \\
\text { objetivos já fixados, análise da } \\
\text { produtividade em organizaçôes } \\
\text { em } P \& D \text {, análise do retomo de } \\
P \& D \text { a partir de um quadro de } \\
\text { referências. }\end{array}$ \\
\hline
\end{tabular}

6Tidd et alii (1996) apontam o trabalho de Edwards e Gordon, publicado em 1984, como o primeiro a medir inovação utilizando anúncio de produtos.

Fonte: Elaboração própria a partir de Andreassi, 1999

Andreassi (1999) analisou as relações entre o esforço de P\&D e os resultados obtidos pelas empresas brasileiras, procurando estudar o grau de associação entre uma série de indicadores de intensidade de P\&D (despesa em P\&D), de resultado de P\&D (patentes) e de resultado empresarial (lucratividade, faturamento, participação do mercado, faturamento gerado por produtos novos ou melhorados). 0 estudo deu origem a tabela 2 , a seguir, que sintetiza os principais resultados encontrados na literatura: 
Tabela 2: Relações entre indicadores de P\&D e indicadores empresarias no Brasil

\begin{tabular}{|c|c|c|}
\hline Relação entre: & Indicadores & Resultados encontrados \\
\hline $\begin{array}{l}\text { Inputs } \\
\text { (intensidade) e } \\
\text { Outputs }\end{array}$ & Gastos em $P \& D$ e patentes & $\begin{array}{l}\text { Andreassi cita os trabalhos realizados por Soete e } \\
\text { Bound at al (1984) que encontraram boa } \\
\text { conrelação entre gastos em } \mathrm{P} \& \mathrm{D} \text { por funcionário e }\end{array}$ \\
\hline (resultado) & & $\begin{array}{l}\text { patentes por fimcionario. No entanto os dois } \\
\text { autores afirmam que esse indice sofre grande } \\
\text { influência do tamanho da empresa, já que quanto } \\
\text { maior a empresa mais gastos ela deve ter com } \\
\mathrm{P} \& \mathrm{D} \text {. Assim, pequenas empresas que fazem } \mathrm{P} \& \mathrm{D} \\
\text { tendem a patentear mais por dólar dispêndido do } \\
\text { que grandes empresas. }\end{array}$ \\
\hline $\begin{array}{l}\text { Inputs } \\
\text { (intensidade)e } \\
\text { Outcomes } \\
\text { (resultados } \\
\text { empresariais) }\end{array}$ & Gastos em P\&D e lucratividade & $\begin{array}{l}\text { Relação controversa. Alta correlação quando } \\
\text { considerados valores absolutos (Parasuraman e } \\
\text { Zeren, 1983). Considerando-se valores relativos, a } \\
\text { correlação depende do setor analisado (Morbey, } \\
\text { 1989). }\end{array}$ \\
\hline $\begin{array}{l}\text { Inputs } \\
\text { (intensidade)e } \\
\text { Outcomes } \\
\text { (resultados } \\
\text { empresariais) }\end{array}$ & Gastos em $P \& D$ e faturamento & $\begin{array}{l}\text { A relação entre gastos em } \mathrm{P} \& \mathrm{D} \text { e } \\
\text { lucratividade é bastante controversa, tendo } \\
\text { sido encontrados na literatura tanto autores } \\
\text { que comprovam uma associação positiva } \\
\text { entre essas duas variáveis (mas para apenas } \\
\text { alguns setores de atividade), quanto autores } \\
\text { que não conseguiram correlacioná-las. } \\
\text { Odagiri (1983) efetuou um estudo com } 370 \\
\text { empresas japonesas onde realizou correlações } \\
\text { entre a taxa de crescimento no faturamento no } \\
\text { periodo } 1969-1981 \text { e os gastos em } P \& D \text { por } \\
\text { faturamento nos periodos } 1969-1972 \text { e } 1978- \\
\text { 1981. Considerando a amostra total e os } \\
\text { setores mais inovadores, a correlação entre } \\
\text { crescimento no faturamento e gastos em } P \& D \\
\text { por faturamento em periodos precedentes é } \\
\text { levemente superior à correlação entre } \\
\text { crescimento no faturamento e gastos em } P \& D \\
\text { por faturamento em periodos posteriores, } \\
\text { indicando que é a intensidade em } P \& D \text { que } \\
\text { leva a um crescimento no faturamento e não o } \\
\text { oposto. Morbey e Reithner (1990) e Brenner } \\
\text { e Rushton (1989) encontraram correlação } \\
\text { positiva significativa entre gastos em } P \& D \text { e } \\
\text { crescimento no faturamento em periodos } \\
\text { subsequientes. Brenner e Rushton (1989) não } \\
\text { encontraram correlação entre crescimento no } \\
\text { faturamento e gastos em } P \& D \text { em periodos } \\
\text { subsequientes. }\end{array}$ \\
\hline $\begin{array}{l}\text { Inputs } \\
\text { (intensidade)e } \\
\text { Outcomes } \\
\text { (resultados } \\
\text { empresariais) }\end{array}$ & $\begin{array}{c}\text { Gastos em P\&D e participação } \\
\text { de mercado }\end{array}$ & $\begin{array}{l}\text { A teoria schumpeteriana diz que estruturas } \\
\text { oligopolisticas propiciam a inovação, embora } \\
\text { Matesco (1993) afine que outras variáveis } \\
\text { possam estar interferindo no processo, como por } \\
\text { exemplo o grau de rivalidade do setor. Chandler } \\
\text { afirma que nas industrias tecnologicamente } \\
\text { avançadas, melhorias nos produtos e processos } \\
\text { são anmas para manter e ampliar o mercado. }\end{array}$ \\
\hline
\end{tabular}




\begin{tabular}{|c|c|l|}
\hline $\begin{array}{c}\text { Inputs } \\
\text { (intensidade)e } \\
\text { Outcomes } \\
\text { (resultados } \\
\text { empresariais) }\end{array}$ & $\begin{array}{c}\text { Gastos em P\&D e novos } \\
\text { produtos }\end{array}$ & $\begin{array}{l}\text { Wolff (1995) observou forte conrelação positiva } \\
\text { entre as variaveis. Indicador fäcil de se obter, as } \\
\text { empresas geralmente sabem, com certo grau de } \\
\text { precisão, se seu mix de produtos mudou ou não. }\end{array}$ \\
\hline $\begin{array}{c}\text { ResultadoOutp } \\
\text { ut e resultados } \\
\text { empresariais } \\
\text { (outcome) }\end{array}$ & $\begin{array}{c}\text { Patentes e participação de } \\
\text { mercado }\end{array}$ & $\begin{array}{l}\text { Scherer (1965) não encontrou correlação } \\
\text { significativa. }\end{array}$ \\
\hline $\begin{array}{c}\text { Resultado } \\
\text { Output e } \\
\text { resultados } \\
\text { empresariais } \\
\text { (outcome) }\end{array}$ & Patentes e lucratividade & $\begin{array}{l}\text { Scherer (1965) não encontrou conrelação } \\
\text { significativa. }\end{array}$ \\
\hline $\begin{array}{c}\text { Resultado } \\
\text { Output e } \\
\text { resultados } \\
\text { empresariais } \\
\text { (outcome) }\end{array}$ & Patentes e faturamento & $\begin{array}{l}\text { Odagini (1983) cita os trabalhos de Scherer e de } \\
\text { Branch. os quais encontraram conrelação positiva } \\
\text { e significativa entre patentes e evolução no } \\
\text { faturamento. }\end{array}$ \\
\hline
\end{tabular}

Fonte: Modificado de Andreassi (1999).

O autor efetuou uma revisão bibliográfica visando colher subsídios para a formulação de onze hipóteses envolvendo os indicadores acima mencionados. Tais hipóteses foram testadas a partir de dados provenientes de 125 empresas informantes da Base de Dados sobre Indicadores Empresariais de Inovação Tecnológica, implementada desde 1992 pela ANPEI Associação Nacional de Pesquisa e Desenvolvimento das Empresas Inovadoras. Conforme pode ser observado, os resultados obtidos apontaram para a não existência de correlação dos indicadores de lucratividade ou participação de mercado com os indicadores de intensidade de $P \& D$ ou resultado de $P \& D$, indicando que muitas outras variáveis que não despesas em $P \& D$ ou patentes intervém no processo.

Quanto à correlação dos indicadores de intensidade ou resultado de P\&D com a evolução do faturamento bruto, o estudo revelou que os gastos efetuados pelas empresas em P\&D, no Brasil, ainda estão muito atrelados aos resultados obtidos pelas mesmas, contrariando diversos autores que recomendam que os investimentos em P\&D sejam mantidos razoavelmente constantes ao longo do tempo.

0 indicador faturamento gerado por produtos novos ou melhorados foi, dentre todos os indicadores de resultado empresarial considerados neste trabalho, o que apresentou maior correlação com os indicadores de intensidade/resultado de P\&D. Tal fato sugere a importância da empresa manter uma política consistente de apoio à $\mathrm{P} \& \mathrm{D}$, uma vez que, em média, os produtos novos representaram 37\% do faturamento das empresas aqui analisadas. Os resultados da análise correlacional foram, de certa forma, validados pela aplicação da análise de correlação canônica, uma técnica multivariada na qual todos os indicadores foram considerados simultaneamente.

Segundo Hauser et al (1996), para programas de PD\&E que criam novas ou combinam as competências tecnológicas já existentes, os indicadores de resultados também chamados de indicadores de outcomes precisam ser balanceados com indicadores de esforços inovativo. 0 aumento do "peso do mercado" em indicadores de PD\&E podem levar a falsa rejeição de projetos promissores, já que encoraja a seleção de programas de menor valor que estão concentrados em um número pequenos de subunidades de negócio, mas com maior segurança de resultados. No entanto, para alinhar PD\&E e as metas econômicas da firma, o sistema de indicadores deve balancear os indicadores de resultados de mercado com 
indicadores que tentam medir mais diretamente os esforços de pesquisa diretamente. Alguns desses indicadores incluem os indicadores tradicionais.

Ainda em Hauser, para a melhor compreensão de como os indicadores podem variar de acordo com o tipo de pesquisa realizada, é usada uma metáfora de níveis. A metáfora permite categorizar diversos projetos, programas e explorações e focar nas características chaves de cada um. Ele define "nível 1" como a pesquisa básica que tenta entender a ciência básica e a tecnologia podendo ser aplicadas a várias unidades de negócio, inclusive a novas unidades. 0 "nível 2", ele define como as atividades que selecionam e desenvolvem programas para criar ou combinar a competência tecnológica da organização. 0 "nível 3" é definido como projetos mais específicos focados em necessidades imediatas de clientes, da unidade empresarial ou da própria corporação. Indicadores que funcionam bem para uma instituição ou para uma atividade podem não funcionar bem para outra. Assim, segundo recomendações da pesquisa do MIT (Massachusetts Institute of Technology), a tabela 3 a seguir sumariza a variedade de indicadores usados para avaliar e dirigir o programa de PD\&E classificados de acordo com a metáfora de níveis.

Tabela 3: Indicadores de PD\&E segundo Metáfora de Níveis

\begin{tabular}{|c|c|}
\hline Níveis & Detalhamento \\
\hline Nivel 1: Pesquisa básica e exploração & $\begin{array}{l}\text { 1. Encorajamento de Benchmarketing } \\
\text { 2. Indicadores baseados em todas as } \\
\text { idéias } \\
\text { 3. Indicadores que premiam pessoas por } \\
\text { idéias internas. }\end{array}$ \\
\hline $\begin{array}{l}\text { Nivel 2: Programas para criar ou combinar } \\
\text { competências tecnológicas. }\end{array}$ & $\begin{array}{l}\text { 1. Indicadores que reconheçam a } \\
\text { diferença entre decisões no programa e } \\
\text { decisões em projetos } \\
\text { 2. Indicadores que reconheçam que } \\
\text { reconheçam que a escolha do } \\
\text { programa de pesquisa é crítico e } \\
\text { acontece antes da maioria dos esforços } \\
\text { científicos, de engenharia e de projeto } \\
\text { 3. Indicadores de medidas de resultados } \\
\text { de mercado devem ser levados em } \\
\text { conta mas com baixo peso. } \\
\text { 4. O programa de PD\&E deve encorajar } \\
\text { os esforços corretos. Isso requer que } \\
\text { os indicadores de esforços balanceiem } \\
\text { os indicadores de custo } \\
\text { Indicadores tradicionais. }\end{array}$ \\
\hline $\begin{array}{l}\text { Nível 3: Projetos aplicados com ou para } \\
\text { unidades comerciais. }\end{array}$ & $\begin{array}{l}\text { 1. As unidades comerciais não devem ter } \\
\text { total autonomia na decisão dos } \\
\text { indicadores para que não escolham } \\
\text { projetos com retorno a curto prazo ou } \\
\text { menos arriscados } \\
\text { 2. Subsídios podem ser usados para que } \\
\text { compensar outros termos como curto } \\
\text { prazo, riscos, etc. } \\
\text { 3. Novos caminhos devem ser } \\
\text { mensurados para avaliar uma possível } \\
\text { flexibilidade em novas decisões } \\
\text { tomadas pela empresa no decorrer do } \\
\text { projeto. Isso fará com que a empresa } \\
\text { aceite riscos mais facilmente }\end{array}$ \\
\hline
\end{tabular}

Fonte: Elaboração própria, a partir de Hauser, 1996 
Os indicadores sugeridos por Hauser são divididos em dois grandes grupos de análise e alocados nos níveis da metáfora. Esses grandes grupos são: o "julgamento qualitativo", cujos indicadores não são realmente mensuráveis, mas devem ser levados em consideração na hora da decisão; e "medidas quantitativas", que são os indicadores propriamente dito e que permitem comparação com outras empresas do setor. A tabela 4 a seguir sumariza esses indicadores.

Tabela 4: Indicadores X Níveis da Metáfora de Hauser

\begin{tabular}{|c|c|c|c|}
\hline \multirow[t]{2}{*}{$\begin{array}{l}\text { "Julgamento } \\
\text { Qualitativo" }\end{array}$} & Categoria & Indicador & \multirow{2}{*}{$\begin{array}{c}\begin{array}{c}\text { Niveis } \\
\text { Relevantes }\end{array} \\
\text { Nivel } 2 \\
\text { Nivel } 2 \\
\text { Nivel 2 } \\
\end{array}$} \\
\hline & $\begin{array}{l}\text { Objetivos } \\
\text { Estratégicos }\end{array}$ & $\begin{array}{l}\text { Convergência com os objetivos } \\
\text { estratégicos da organização } \\
\text { Escopo da tecnologia } \\
\text { Efetividade de um novo sistema }\end{array}$ & \\
\hline & Qualidade/Valor & $\begin{array}{l}\text { Qualiclade da pesquisa } \\
\text { Revisão minuciosa da pesquisa } \\
\text { Comparação de atividades de pesquisa } \\
\text { através de benchmarking } \\
\text { Valor das } 5 \text { maiores entregas }\end{array}$ & $\begin{array}{l}\text { Nivel } 1,2,3 \\
\text { Nivel } 2,3 \\
\text { Nivel } 2,3 \\
\text { Nivel } 3\end{array}$ \\
\hline & Pessoas & $\begin{array}{l}\text { Qualiclade das pessoas } \\
\text { Envolvimento gerencial }\end{array}$ & $\begin{array}{c}\text { Nivel } 1 \\
\text { Nivel } 2.3\end{array}$ \\
\hline & Processo & $\begin{array}{l}\text { Produtividade } \\
\text { Tempo de resposta }\end{array}$ & $\begin{array}{l}\text { Nivel } 3 \\
\text { Nivel } 3 \\
\end{array}$ \\
\hline & Cliente & Relevância & Nivel 2 \\
\hline \multirow{12}{*}{$\begin{array}{c}\text { Medidas } \\
\text { Quantitativas }\end{array}$} & $\begin{array}{c}\text { Objetivos } \\
\text { Estratégicos }\end{array}$ & $\begin{array}{l}\text { Número de inovações } \\
\text { Patentes } \\
\text { Citações de artigos } \\
\text { Resposta competitiva }\end{array}$ & $\begin{array}{l}\text { Nivel } 2 \\
\text { Nivel } 2 \\
\text { Nivel } 1,2 \\
\text { Nivel } 3 \\
\end{array}$ \\
\hline & Qualidade/Valor & $\begin{array}{l}\text { Conceitos de sucesso } \\
\text { Porcentagem de metas atingidas }\end{array}$ & $\begin{array}{l}\text { Nivel } 3 \\
\text { Nivel } 1,2\end{array}$ \\
\hline & Processo & $\begin{array}{l}\text { Medidas de processos intemos } \\
\text { Entregas realizadas } \\
\text { Preenchimento de especificações técnicas } \\
\text { Tempo para completação } \\
\text { Velocidade de utilização de tecnologia para } \\
\text { geração de novos produtos } \\
\text { Tempo para o mercado } \\
\text { Tempo de resposta para problemas com } \\
\text { clientes }\end{array}$ & $\begin{array}{l}\text { Nivel 1,2 } \\
\text { Nivel } 3 \\
\text { Nivel } 3 \\
\text { Nivel } 3 \\
\text { Nivel } 3 \\
\\
\\
\text { Nivel } 3 \\
\text { Nivel } 3\end{array}$ \\
\hline & & Satisfação do cliente & Nivel 3 \\
\hline & & Qualidade do serviço & Nivel 3 \\
\hline & Cliente & $\begin{array}{l}\text { Número de clientes que identificaram } \\
\text { fallhas }\end{array}$ & Nivel 3 \\
\hline & & $\begin{array}{l}\text { Receitas de novos produtos (3 anos) } / \\
\text { investimento em P,D\&E } \\
\% \text { Receitas derivadas de produtos de } 3-5 \\
\text { anos }\end{array}$ & $\begin{array}{l}\text { Nivel } 3 \\
\text { Nivel } 3\end{array}$ \\
\hline & Receitas/Custos & Margem bruta sobre novos produtos & Nivel 3 \\
\hline & & Valor econômico adicionado & Nivel 3 \\
\hline & & Break Even após lançamento & Nivel 3 \\
\hline & & Custo de comprometimento futuro & Nivel 2,3 \\
\hline & & Custo adicional de pesquisa & Nivel $1,2,3$ \\
\hline
\end{tabular}

Fonte: Elaboração própria, a partir de Hauser, 1996 
O Manual Rationalization des Choix Budgetaireis, editado em 1986 pelo Governo da França e citado em Cruz (2005), Liberal (2003) e Tabela 5 - Indicadores relacionados no Manual Rationalization des Choix BudgetaireisSanchez e Paula (2001), prediz que a formulação e análise de indicadores devem ser articuladas em níveis segundo sua utilização: de entrada, de saída, de estado e de gestão. 0 manual aponta ainda alguns indicadores a serem analisados para avaliação do grau de inovação, conforme listado na tabela 5:

Tabela 5: Indicadores relacionados no Manual Rationalization des Choix Budgetaireis

\begin{tabular}{|l|}
\hline Indicadores de inovação \\
\hline Números de pessoas alocadas na empresa que adquiriam qualificação \\
\hline Proporção de vendas devido a produtos/processos novos ou melhorados \\
\hline Proporção no faturamento da empresa devido a produtos/processos novos ou melhorados \\
\hline Proporção de redução de custos da empresa \\
\hline Indicadores de processo \\
\hline Demandas tecnológicas atendidas \\
\hline Processos novos \\
\hline Processos melhorados \\
\hline Indicadores de produto \\
\hline Patentes requeridas \\
\hline Patentes concedidas \\
\hline Demandas tecnológicas atendidas \\
\hline Produtos melhorados \\
\hline Produtos novos ou novas aplicações \\
\hline
\end{tabular}

\section{PRINCIPAIS CONCLUSÕES:}

Várias conclusões podem ser extraídas do trabalho, como por exemplo:

- Ao se relacionar planejamento estratégico e medidas de desempenho, e importante a compreensão dos membros de uma organização do quanto fundamental é seu trabalho no alcance das estratégias e dos objetivos organizacionais.

- A competitividade, palavra de ordem nos dias atuais, requer não apenas a definição e a execução correta da estratégia empresarial, mas que ambas sejam elaboradas de tal forma que assegurem a eficácia da organização.

- A utilização dos indicadores só fará sentido e terá êxito se as ações organizacionais estiverem alinhadas não somente com as estratégias, mas também com os objetivos da organização.

- Uma adequada mensuração age como ferramenta de fundamental na contribuição na cadeia de decisão e estimula a definição de indicadores destinados a evidenciar a necessidade de ações de melhoria, bem como identificar se as ações implementadas estão surtindo os efeitos desejados.

- Avaliar desempenho é, basicamente, gerenciar de resultados. 
- Qualidade tornou-se um ponto determinante de sucesso em muitos aspectos na sociedade contemporânea. Com a evolução do conceito de qualidade a satisfação das necessidades dos clientes passou a ser um fator ainda mais fundamental para a sobrevivência e prosperidade das organizações no longo prazo.

- É inegável a importância da medição e avaliação do desempenho nas organizações, tendo elas implementado ou não sistemas formais de gestão da qualidade.

- O estabelecimento de uma plataforma para a coleta de dados e elaboração de informações, além de proporcionar facilidades para o fluxo destas por toda a empresa, é primordial para monitorar os ambientes internos e externos.

- É a informação que orienta o planejamento estratégico da organização, fixando os objetivos voltados à satisfação dos clientes, baseados nos indicadores sugeridos pelos próprios.

\section{BIBLIOGRAFIA}

- ANDREASSI, Tales. Estudo das relações entre indicadores de P\&D e Indicadores de resultado empresarial em empresas brasileiras. Tese de doutorado - Faculdade de Economia, Administração e Contabilidade da Universidade de São Paulo - São Paulo, 1999.

- ANPEI. Dispêndios empresariais de inovação tecnológica no Brasil: resultados da base de dados ANPEI (ano base 1996). ANPEI, São Paulo, 1998.

- AQUINO, André Carlos Busanelli de. Sistema de apoio ao processo decisório: a gestão econômica utilizando indicadores balanceados nas decisões estratégicas e de longo prazo. São Carlos, 2001. Dissertação (Mestrado) - Escola de Engenharia de São Carlos,Universidade de São Paulo.

- ARUNDEL, Anthony et. al. The Future of Innovation Measurement in Europe. STEP Group, IDEA Paper Series 3, 31 july 1998.

- ARCHIBUGI, D.; EVANGELISTA, E.; SIMONETTI, R. Concentration, firm size and innovation: evidence from innovation costs. Technovation, v. 15, n. 3, p. 153- 163, 1995.

- BASTOS, C.P.M.; REBOUÇAS, M.M.; BIVAR, W.S.B. A construção da pesquisa industrial de inovação: Pintec. In: VIOTTI, E.B.;MACEDO,M.M. (Org). Indicadores de ciência, tecnologia e inovação no Brasil. Campinas: Editora da Unicamp, 2003.

- COUTINHO, P. L., WEINBERG, G., BOMTEMPO, J. V., "A inovação tecnológica na indústria petroquímica brasileira”, In: 7º CONGRESSO BRASILEIRO DE PETROQUÍMICA, Rio de Janeiro, Brasil, setembro, 2001.

- COUTINHO, P. L. - Estratégia tecnológica e gestão da Inovação: uma estrutura analítica voltada para os administradores de empresas - Rio de Janeiro, 2004. Tese (Doutorado) Universidade Federal do Rio de Janeiro - UFRJ, Escola de Química - EQ

- CRUZ, Rosane. Valores dos empreendedores e inovatividade em pequenas empresas de base tecnológica. Tese (Doutorado) - Programa de pós-graduação em Administração da Universidade federal do Rio Grande do Sul. Porto Alegre, 2005.

- CAMPBELL, A.; ALEXANDER, M. What's wrong with strategy? Insights about valuecreation 
rarely emerge from planning processes. Harvard business review 75, n.6. Boston,p.2-8, nov./dec. 1997.

- FAPESP - Inovação Tecnológica na Indústria Paulista: uma análise com base nos resultados da pesquisa. Pintec, 2005

- FROST, Bob. Performance Metrics: The New Strategic Discipline. Chicago: Strategy \&Leadership, a publication of Strategic Leadership Forum, p. 34 - 35, mai - june 1999.

- HAUSER, John R., Zettelmeyer, Florianc M. Metrics to Evaluate R,D\&E nov, 1996

- HAUSER, John R., Katz, Gerald M. Metrics: You are what you measure! Abril, 1998

- KAPLAN, Robert S.; NORTON, David P. A estratégia em ação. Rio de Janeiro: Campus,1997.

- LIBERAL, Claudemir Gonçalves. Indicadores de Ciência, tecnologia e inovação do Paraná: um estudo matricial. Programa de pós-graduação em Tecnologia do Centro Federal de Educação tecnológico do Paraná (CEFET/PR). Curitiba, 2003.

- LUNDVALL, B. (ed.) National systems of innovation: towards a theory of innovation and interactive learning, London: Pinter, 1992.

- MAFRA, Antero Tadeu. Proposta de indicadores de desempenho para a indústria de cerâmica vermelha. 1999. Dissertação (Mestrado em Engenharia de Produção) - Programa de Pós Graduação em Engenharia de Produção, UFSC, Florianópolis.

- MANUAL DE FRASCATI 2002- ISBN 84-688-2888-2 - C OCDE 200

- MARCCELLI, Ricardo Pereira. O papel dos indicadores de desempenho na estratégia das organizações para o aprimoramento de processos: um estudo de caso. 2000. Dissertação (Mestrado em Engenharia de Produção) , UFSC, Florianópolis.

- MEYER, Christopher. How the right measures help teams excel. Boston: Harvard business review, p.94-103, mai - jun. 1994.

- MINTZBERG, Henry; AHLSTRAND, Bruce; LAMPEL, Joseph. Safári de estratégia: um roteiro pela selva do planejamento estratégico. Porto Alegre: Bookman, 2000.

- NELSON, R. R. National innovation systems: a comparative analysis. Oxford Univ. Press, 1993.

- OCDE. Manual de Oslo: OECD proposed guidelines for collecting and interpreting technological innovation data. Paris, 1996.

- PALEIAS, Ivam Ricardo. Avaliação de desempenho: um enfoque de gestão econômica. Dissertação (mestrado) - Faculdade de Economia, Administração e Contabilidade, Universidade de São Paulo, 1992

- PATEL, Pari; PAVITT, Keith. Patterns of Technological Activity: their measurement and interpretation. In: Stoneman, Paul. Handbook of Economics of Innovattion and Technological Change. Oxford, 1995 p. 14-51.

- PINO, Jefferson de Souza; RIOS, José Antonio Dermengi. A necessidade de novos 
paradigmas em indicadores de desempenho de inovação para empresas

- PROBST, G. et al. Gestão do conhecimento: os elementos construtivos do sucesso. Porto Alegre: Bookman, 2002.

- ROCHA, Elisa Maria Pinto; FERREIRA, Marta Araújo Tavares."Análise dos Indicadores de Inovação Tecnológica no Brasil: comparação entre um grupo de empresas privatizadas e o grupo geral de empresas". Ciência e Informação, Brasília, v. 30, n. 2, p. 64-69, maio/ago, 2001

- RUMMLER, Geary A.; BRACHE, Alan P. Melhores desempenhos das empresas. São Paulo: Makron Books, 1994.

- SBRAGIA, R. Um Estudo sobre os Possíveis Indicadores para Apreciação dos Resultados da Atividade de P\&D em Contextos empresariais. Tese (Livre Docência em Administração) Faculdade de Economia, Administração e Contabilidade, Universidade de São Paulo. São Paulo, 1986.

- SINK, D. Scott; TUTTLE, Thomas C. Planejamento e medição para a performance. Rio de Janeiro: Qualitymark, 1993.

- SMITH, K. Innovation indicators and the knowledge economy: concepts, results and policy challenges. Oslo: STEP Group, 2000.

- WALTON, Richard E. Tecnologia de informação: o uso de TI pelas empresas que obtêm vantagem competitiva. São Paulo: Atlas, 1993. 